\title{
Social Network Position and Its Relationship to Performance of IT Professionals
}

\author{
Paul Burton \\ Project Manager
}

pburton3@hotmail.com

\author{
Yu "Andy" Wu and Victor R. Prybutok \\ University of North Texas \\ Denton, TX, USA
}

\author{
andy.wu@unt.edu; \\ victor.prybutok.unt.edu
}

\begin{abstract}
An important informing channel for information technology professionals and other knowledge workers is their social networks. Taking the perspective of the transdisciplinary social capital theory, this study explores the relationship between information technology professionals' social network positions and job performance. We operationalized their network positions as their network constraint, i.e., inability to bridge structural holes in social networks. Social network analysis on data collected from information technology professionals at a large defense company revealed a network woven by 371 people. Logistic regression results showed a significant, inverse relationship between performance and constraint. Therefore, network constraint appears to be an informer/client characteristic that influences his/her ability to take advantage of social networks as an informing channel and to improve performance.
\end{abstract}

Keywords: Social networks, performance, social capital, constraint, structural hole, informing channel

\section{Introduction}

The job performance of information technology (IT) professionals, to a large degree, depends on their technical and organizational knowledge. The successful IT professional constantly updates his/her knowledge to remain abreast of new technologies, changes in organizational strategies, and current affairs in other organizational units (Major et al., 2007). An important way to be informed in such a manner is to tap one's social networks. Through these networks a person stays attuned to the organization's mission and gains tacit organizational knowledge (McCluskey \& Korobow, 2009). Social networks mediate the effect of human resource practices on knowledge transfer (Kaše, Paauwe, \& Zupan, 2009). To truly understand how various organizational units use technologies, IT professionals must factor in social networks because the networks influence

Material published as part of this publication, either on-line or in print, is copyrighted by the Informing Science Institute. Permission to make digital or paper copy of part or all of these works for personal or classroom use is granted without fee provided that the copies are not made or distributed for profit or commercial advantage AND that copies 1) bear this notice in full and 2) give the full citation on the first page. It is permissible to abstract these works so long as credit is given. To copy in all other cases or to republish or to post on a server or to redistribute to lists requires specific permission and payment of a fee. Contact Publisher@InformingScience.org to request redistribution permission. system use (Sykes, Venkatesh, \&

Gosain, 2009).

The potency of social networks comes from the social capital they embody. Social capital refers to the advantage an individual obtains via being connected to others. This advantage is created by a person's location in the structure of network relationships. Social capital "explains how people do better because they are somehow better connected with 
other people (Burt, 2005, p. 4)." For knowledge workers, social capital established in their social network enables them to be better informed - exposed to valuable job-related information (Brookes, Morton, Grossman, Joesbury, \& Varnes, 2007; Lee, Wong, \& Chong, 2005).

Therefore, as knowledge workers, IT professionals' job performance is likely to be affected by their social network positions, a relationship that seems to remain largely unexplored to date. Our study is an early investigation of this relationship. It also contributes to the transdiscipline of informing science because informing channel is one of the four research areas that $\mathrm{E}$. B. Cohen (2009) proposes in his latest update to his seminal work on informing science (E. B. Cohen, 1999). Cohen also suggests the scrutiny of informer/client characteristics for their impact on informing channels. Accordingly, in this paper we take the perspective of a person's network constraint, or equivalently, his/her ability to bridge structural holes in social networks, and study its effect on performance. The lower the constraint, the better the person's ability to tap the social capital embodied in his/her social networks. Hence, we hypothesize an inverse relationship between IT professionals' network constraint and their performance, especially their ability to exceed job performance expectations. We empirically tested this hypothesis, controlling for human capital variables such as job tenure (years of service), age, and job grade (technical versus managerial position, middle versus senior management). Figure 1 shows the research model.

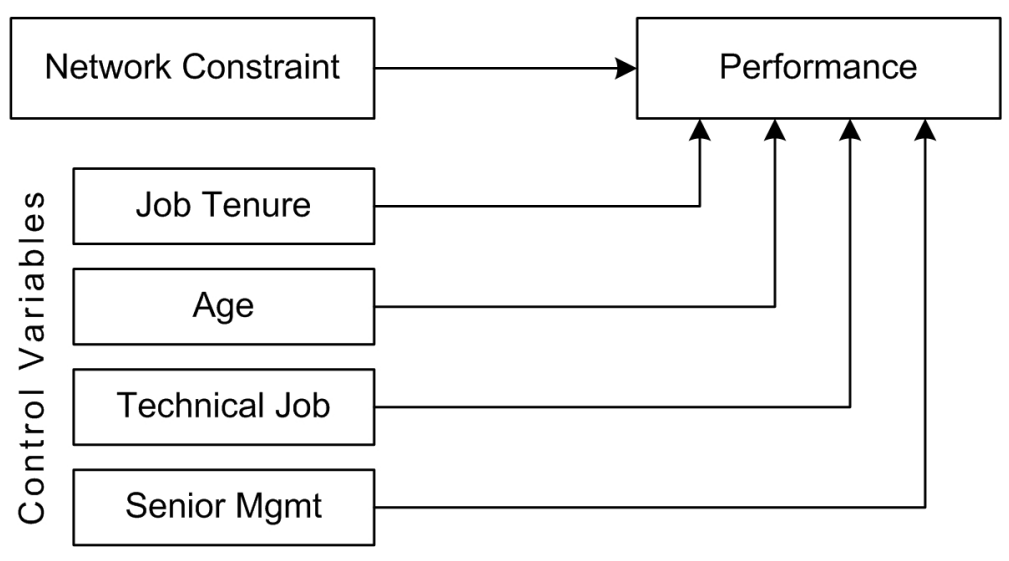

Figure 1. Research Model

The remainder of this paper is organized in the following manner. First, we review the current literature on social capital and social networks, especially as related to structural holes in social networks. Next, we propose our main research hypothesis, followed by a description of the data collection process. We then report our data analysis results. Finally, we discuss our major findings and recommend future research directions.

\section{Theoretical Foundation}

\section{Social Capital}

Social capital is well suited for transdisciplinary studies. Rooted in sociological studies 30-40 years ago, it has seen application to a wide variety of disciplines (Yang, Lee, \& Kurnia, 2009) and has become a core concept in business, political science, and sociology. Social capital is defined, at the individual level, as the potential resources inherent in an individual's set of social ties. At the organizational level, social capital leads to the "benefits that accrue to the collectivity as a result of the maintenance of positive relations between different groups, organizational units, or hierarchical levels" (Kilduff \& Tsai, 2003, p. 26). 
A central component of social capital is the development of individuals by forming relationship networks of people in key groups, departments, or organizations. Individuals develop network ties with others. These ties actually become a source of social capital (Inkpen \& Tsang, 2005, p. 7).

Many studies were done to determine how social capital impacts on learning, performance, and effectiveness (Baker, 2000; Cross \& Parker, 2004; Lin, 1999, 2001). Social capital is claimed to provide significant organizational benefits, including power (Brass, 1984), leadership (Sparrowe \& Liden, 1997), mobility (Boxman, De Graaf, \& Flap, 1991), and employment (Fernandez, Castilla, \& Moore, 2000). An individual's position within social networks can confer advantages such as organizational assimilation (Sparrowe \& Liden, 1997); promotions (Burt, 1992); enhanced knowledge sharing; lower transaction costs due to a high level of trust and cooperative spirit; lower turnover rates; and greater coherence of action due to organizational stability and shared understanding (D. Cohen \& Prusak, 2001).

\section{Social Networks}

Network typology of social capital, or structural capital, focuses on benefits, such as those discussed above, that individuals receive by either occupying a central position within the network (Brass \& Burkhardt, 1993; Powell, Koput, \& Smith-Doer, 1996) or having a network with a certain structure that enables these benefits to be realized (Burt, Hogarth, \& Michaud, 2000; Coleman, 1988). An individual's position in the network is described in terms of a desirable pattern of ties or relationships with other members. The benefits to the individual are principally a function of the topology of the local network, and ties are implicitly conceived of as forming a leverageable structure (Markovsky, Skvoretz, Willer, Lovaglia, \& Erger, 1993). Structural capital studies started with the work of Bavelas (1950) at MIT, who investigated the relation between centralization and group performance (see review by Shaw, 1971) and sought to relate network structure to performance (e.g., Athanassiou \& Nigh, 1999).

Social network analysis has emerged as a tool for studying social capital. A basic tenet of almost all social capital theories is that the network is one of the most powerful assets any individual can possess (D. Cohen \& Prusak, 2001). Social capital is enhanced by an individual's network position in relation to other individuals and is captured from the embedded resources in such networks (Granovetter, 1985; Lin, 1999). The social structure defines the kind of capital that can create competitive advantage (Burt, 2005).

\section{Social Network and Performance}

The theoretical foundation of performance is based on the idea that the structure of social interactions enhances or constrains access to valued resources (Brass, 1984; Ibarra, 1993b). Resources exchanged through informal networks have substantial value, including work-related resources of task advice and strategic formation. This resource exchange is likely to be positively related to job performance (Sparrowe, 2001).

For knowledge workers like IT professionals, their social capital/networks are a valuable source for information and knowledge that can substantially influence their performance. Researchers found that individuals with a high degree of social capital have privileged access to knowledge and information, preferential opportunities for new business, reputation and influence, and enhanced understanding of group norms (Inkpen \& Tsang, 2005). Certain types of social networks can enhance knowledge transfer and learning (Hansen, 1999; Reagans \& McEvily, 2003). Social interaction as a manifestation of the structural dimensions of social capital and trust is significantly related to the extent of interunit resource exchange, which in turn has a significant effect on product innovation (Tsai \& Ghosal, 1998). Given that many IT professionals work in virtual 
collaborative environments, social networks can enhance their performance by overcoming the barriers of lean channels. Robert, Dennis, and Ahuja (2008) find that structural, relational, and cognitive social capital all facilitate knowledge integration and, among the three, structural capital is particularly helpful when the face-to-face communication channel is lacking. Similarly, Wasko and Faraj (2005) find that structural capital plays the most significant role in the knowledge exchange process. The more one is in regular contact with others via his/her networks, the more likely he/she will develop a "habit of cooperation" and the better he/she will understand group norms and expectations.

Network analysis has revealed key aspects of social networks in relation to employee effectiveness, yet there has been relatively little research concerning network position and individual performance (Flap \& Volker, 2004; Mehra, Kilduff, \& Brass, 2001; Sparrowe, 2001). Rather than focusing on direct performance measures, many researchers rely on proxies for performance, such as work satisfaction and commitment (Brass, 1984), absenteeism (Sanders \& Hoekstra, 1998), rank and timing of promotion (Burt, 1992; Erickson, 2001; Podolny \& Baron, 1997), income (Burt, 2000), and influence (Ibarra, 1993a). However, "direct studies on networks and jobperformance are practically non-existent" (Flap \& Volker, 2004, p. 174). Our study, therefore, addresses this void.

\section{Structural Holes and Constraint}

To examine the impact of an employee's social networks on his/her performance, we focus on a key property of this informing channel - structural holes. Individuals within a social network form clusters of friends, such as acquaintances and business associates. Gaps between clusters are holes in the structure of information flow, or more simply, structural holes (Burt, 2005). These structural holes are the empty spaces in social structure, or "gaps in the social world across which there are no current connections" between individuals (Kilduff \& Tsai, 2003). Individuals with a high degree of social capital bridge the gaps created by such holes (Burt, 2005).

People whose network ties bridge the holes "are brokers rewarded for their integrative work. They are rewarded in the sense of more positive individual and team evaluations" (Burt, 2005, p. 7). Research has shown that individuals who can effectively span structural holes gain greater advantages. Senior managers who span structural holes are more likely to be promoted early (Podolny \& Baron, 1997). Loan officers with networks that span structural holes were shown to be more likely to bring a deal to closure (Mizruchi \& Sterns, 2001). In a French chemical firm, salary increases were more likely for individuals who span structural holes (Burt et al., 2000). Mehra, Kilduff, and Brass (2001) found that supervisors in a small technology company gave higher performance evaluations to employees whose networks bridged otherwise disconnected parts of their organizations. These individuals are able to access more information by being exposed to more new and varied bits of information, and in turn become more effective employees (Burt, 2005).

The "bridging of structural holes" can be measured in multiple ways. Burt (2000) notes that, "even a simple count of bridge relationships seems to work; people with more bridges do better" (p. 33). The more concise method to measure brokerage of structural holes is through the amount of closure in the network, determined by constraint. Constraint can be considered a measure of an individual's inability to span structural holes (and therefore possess less social capital). An individual can be constrained in a network if (a) he/she has too few contacts; (b) he/she has contacts closely connected with one another; or (c) he/she shares information indirectly via a central contact. 


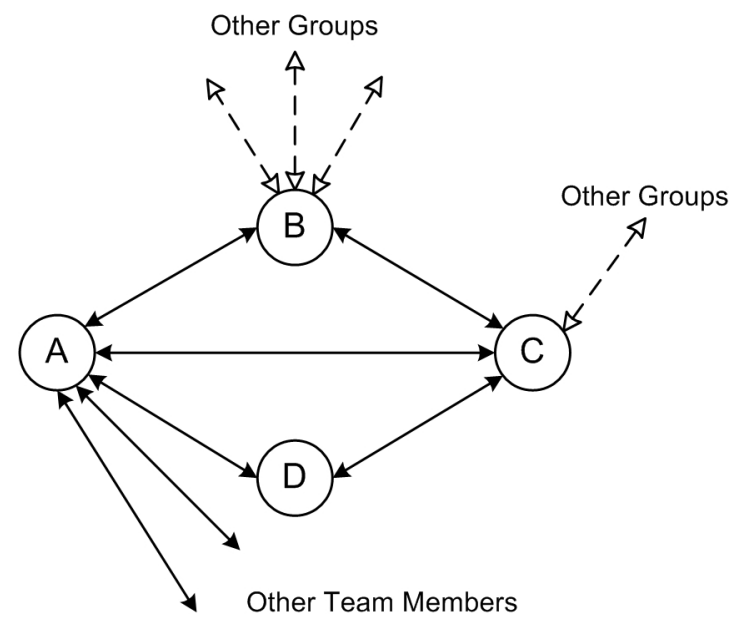

Figure 2. Network Constraint

As a fictitious example (Figure 2), a software engineer, "Person A," may be a member of a development team, which has become a closely-knit group. Team members are connected to each other with a large number of direct and indirect links. $\mathrm{A}$ is connected to $\mathrm{C}$ not only through a direct link but also indirectly through her connections to $\mathrm{B}$ and $\mathrm{D}$, because the latter two also have direct connections to $\mathrm{C}$. As a result, the amount of network time and energy that A invests in networking has a high likelihood of repeatedly leading back to $\mathrm{C}$. The redundancy is high, meaning that it is very likely that A will receive the same information multiple times from multiple members (Burt, 1992). In social networks terminology, these team members have "strong ties" (indicated by the solid lines in Figure 2), which foster the homogeneity of the group. In contrast, team members may maintain "weak ties" (dashed lines in figure) to members in other groups. "Weak ties" are a major source of new information and perspectives and are the foundation for a person's ability to bridge network holes (Burt, 1992; Granovetter, 1973, 1983). The higher the number of team members with few or no external ties (e.g., $\mathrm{C}$ and $\mathrm{D}$ in the figure) that $\mathrm{A}$ is connected to, the more constrained A becomes, because she has fewer opportunities for crossing the holes in the network through those connections. Also, the higher the percentage of A's other within-group links (as indicated by the two additional arrowed lines connected to A) also leading back to $\mathrm{C}$, the more constrained A becomes, because the redundancy is higher (Burt, 1992). Conversely, if A is a member of a development team where members maintain fewer, less redundant links between each other but more links to external groups, A will be less constrained and will be more likely to obtain novel information and have more options in reaching out to other groups.

Constraint is measured through a constraint index, a concentration measure that illustrates the extent to which all of a person's network time and energy is concentrated on one contact (Burt, 1992). An individual with high constraint typically depends on one or only a small number of individuals within the network, therefore being exposed to less varied information and unable to expand his or her social capital (Burt, 2005). An individual with a high degree of constraint will be less able to span structural holes hence less positive performance evaluations, while individuals whose discussion networks spanned numerous structural holes had twice the odds of obtaining an outstanding performance rating (Burt, 1992). Thus, there should be a negative association with an IT professional's network position and his/her performance.

\section{Method}

The main hypothesis of this study is that an inverse relationship exists between network position and performance. Network position was measured as constraint. Employee performance was the 
dependent variable and measured by annual performance appraisal ratings obtained from company human resources (HR) records. We also included traditional human capital variables of age, tenure (years of service), and job rank as control variables.

A social network analysis (SNA) was conducted with an Information Technology (IT) department of a large (80,000+ employees) defense company. The sample was nominees for a leadershiptraining program. The company sponsor sent an email to candidates announcing the social network survey followed by a link to the Web-based form to complete the survey. We used "name generators," a widely recognized method (Knoke \& Yang, 2008; Marsden, 1987, 1990) for social network data collection. Using an instrument similar to survey questionnaire, name generators ask a respondent (the "ego") to name those people with whom he/she has social connections (the "alters") and identify and describe every connection he/she has with those alters (the "relationships"). In our study, the survey itself asked the recipients, "Who are the four or five people that you turn to or will turn to in order to best accomplish your goals and objectives as a member of your department?" Respondents listed these individuals, in addition to their years known. The survey included questions to determine relationships between coworkers within the network. Of the 130 employees surveyed, 98 people (the "egos") responded to the survey. The response rate was $75 \%$. Together with the "alters" they named, the resulting list of individuals $(\mathrm{N}=371)$ constituted the network of study. Among these individuals in the network, 3,905 relationships were identified.

\section{Social Network Analysis}

We performed a social network analysis on participant responses to determine the relationships between individuals within the network. From those data a binary matrix was created, which placed senders on each row and recipients on each column. If a link between the two individuals was present, a 1 was placed into that cell. A zero represented the absence of a link. We used the social network analysis package UCINET (Borgatti, Everett, \& Freeman, 1992) to convert these matrices into measures of network position, including constraint. Analysis was then performed in the Statistical Package for the Social Sciences (SPSS) to determine potential relationships among the variables.

Performance was measured by annual performance ratings conducted by the employee's direct manager, obtained from company HR records. Ratings were comprised of three types: (a) meets expectations, (b) exceeds expectations, and (c) far exceeds expectations. Within work organizations, the vast majority of performance ratings come directly from the employees' immediate supervisors (Bretz, Milkovich, \& Read, 1992; Scullen \& Mount, 2000), and often supervisory ratings are considered the most likely valid reflections of true performance (Arvey \& Murphy, 1998). Human capital variables included age, tenure (years of service), and job grade, obtained from company HR records. Job grades were provided on an ordinal scale of 1 to 13, from lower to higher rank.

\section{Data Analysis}

To test the ability of social and human capital variables to predict success or failure to exceed job performance expectations, we performed a logistic regression on the data we collected.

We performed list wise deletion to exclude missing data from the analysis. Afterwards we calculated summary statistics for the variables, including mean, standard deviations, and variance.

Measures of skewness and kurtosis were also calculated to assess the distribution of each variable response set. 
Table 1. Variable Means, Standard Deviations, and Distribution Characteristics

\begin{tabular}{lllll}
\hline Variable & Mean & SD & Skewness & Kurtosis \\
\hline Performance & 1.78 & 0.697 & 0.336 & -0.919 \\
Job Grade & 4.94 & 2.219 & 0.958 & 1.351 \\
Service Years & 15.51 & 10.609 & 0.092 & -1.140 \\
Age & 45.84 & 9.525 & -0.409 & 0.192 \\
Constraint & 0.44 & 0.291 & 0.973 & 0.420 \\
\hline
\end{tabular}

Table 1 summarizes descriptive statistics of the variables, including values for skewness and kurtosis. Skewness refers to the symmetry of the distribution of data points and values outside of a range of -1 to +1 may be considered substantially skewed (e.g., Hair, Black, Babin, Anderson, \& Tatham, 2006). We did not find extreme skewness in the data.

Although for constraint, the levels of skewness and kurtosis were within the acceptable range, it did show a positive skewness with a value close to one. Furthermore, we examined the correlation between constraint and performance and found it marginally significant. To better differentiate the responses in terms of constraint, and to overcome the skewness issue, we converted the variable using the polar extremes method (Hair et al., 2006). This method involves performing contrast coding on a variable and recoding the highest $1 / 3$ of the scores as 0 and the lowest $1 / 3$ of the scores as 1. Applying this procedure, we compared employees with the highest constraint scores (greater than .4993) and those with the lowest scores (less than .2667) and exclude those with moderate constraint scores (between .2667 and .4993). Thus, the dataset used for final analysis contained 229 employees. The polar extreme procedure provides a method of testing focused hypotheses and sharpens the ability to detect differences among groups because it removes the middle group that represents a blend of the characteristics of the two polar extremes (J. Cohen, Cohen, West, \& Aiken, 2003; Hair et al., 2006). After the recoding, Levene's Test result ( $p=$ .355) showed that performance's variances do not differ significantly between the high and low levels of constraint.

As shown in Table 2, there were 13 job classifications, ranging from Tech Analyst I (Classification 1) all the way through Chief Information Officer (Classification 13). This large number of categories could be cumbersome to analyze. However, they clearly represent three types of positions. Accordingly, using two dummy variables, we recoded them into three categories - technical, middle management, and senior management. To facilitate interpretation of results from logistic regression results, we recoded performance, the outcome variable, into a dichotomous variable that indicates whether a person exceeds or fails to exceed performance expectations.

Following Field (2005), we examined the colinearity among the predictor variables by calculating their variance inflation factor (VIF). The VIF values ranged from 1.007 to 2.732, far below the threshold value of 10 (J. Cohen et al., 2003). Therefore, colinearity among the predictors was not a concern. 
Table 2 Job Grades

\begin{tabular}{lll}
\hline Description & HR Classification & Category in Analysis \\
\hline Tech Analyst I & 1 & Technical \\
Tech Analyst II & 2 & Technical \\
Senior Analyst I & 3 & Technical \\
Senior Analyst II & 4 & Technical \\
Principal Analyst & 5 & Middle Management \\
Senior Principal Analyst & 6 & Middle Management \\
Senior Manager & 7 & Middle Management \\
Director & 8 & Senior Management \\
Vice President, Information Systems & 9 & Senior Management \\
Vice President, Information Technology & 10 & Senior Management \\
Information Systems Fellow & 11 & Senior Management \\
Vice President, Enterprise Applications & 12 & Senior Management \\
Chief Information Officer & 13 & Senior Management \\
\hline
\end{tabular}

A logistic regression analysis was then performed to examine the relationships between outcome (whether the employee's performance exceeds expectation) and five predictors: constraint, job grade (technical vs. managerial, middle vs. senior management), tenure, and age. This model with multiple predictors when compared to a constant-only model was statistically reliable, $\chi^{2}(5$, $\mathrm{N}=229)=36.404(p<.001)$, indicating that the predictors, as a set, reliably predicted an employee's performance rating. To be exact, they predicted performance rating correctly for $68.2 \%$ of the employees. The Hosmer and Lemeshow test $\chi^{2}(8, \mathrm{~N}=229)=3.311(p=.913)$ indicated that the model fits the data well. The pseudo- $\mathrm{R}^{2} \mathrm{~s}$ showed that the model explained between $16.1 \%$ (Cox and Snell's $\mathrm{R}^{2}$ ) and 21.9\% (Nagelkerke's $\mathrm{R}^{2}$ ) of the variances in performance rating.

Table 3. Logistic Regression Results

\begin{tabular}{lrrrrrrr}
\hline Predictor & B & S.E. & Wald & Sig. & \multicolumn{2}{c}{$\begin{array}{l}\text { Odds } \\
\text { Ratio }\end{array}$} & \multicolumn{2}{c}{ 95\% C.I.for O.R. } \\
\hline Tenure & -.042 & .018 & 5.558 & .018 & .959 & .926 & .993 \\
Age & -.042 & .022 & 3.620 & .057 & .959 & .919 & 1.001 \\
Constraint & -.606 & .302 & 4.030 & .045 & .545 & .302 & .986 \\
TechJob & -2.439 & .618 & 15.593 & .000 & .087 & .026 & .293 \\
MidMan & -1.471 & .611 & 5.802 & .016 & .230 & .069 & .760 \\
\hline
\end{tabular}

Table 3 shows regression coefficients, Wald statistics, odds ratios, and 95\% confidence intervals for odds ratios for each of the five predictors. According to the Wald criterion, all variables were statistically significant predictors of performance except age $(p=0.057)$, which was marginally 
significant at the .10 level. All coefficients were negative, which signify inverse relationships with the outcome variable. This was consistent with odds ratios that were greater than one. Thus, higher values of tenure were associated with lower values of the outcomes. In other words, the longer one stayed with a position, the less likely that he/she would be rated as exceeding expectations. The negative coefficient $(-2.439)$ for the dummy variable TechMan $(0=$ managerial positions, $1=$ technical positions) indicated that those in managerial positions were more likely to be rated as exceeding expectations than those in technical positions were. The negative coefficient (1.471) for the dummy variable MidMan $(0=$ senior management, $1=$ middle management $)$ revealed that the performance rating of exceeding expectations was easier to achieve for senior managers than for middle management.

The coefficient for the constraint variable (polar extreme coding $0=$ low constraint, $1=$ high constraint) was -.606. Thus, supporting our main hypothesis, an employee who had fewer constraints in the network was more likely to obtain the performance rating of exceeding expectations. In fact, the odds ratio indicated that he/she was $54.5 \%$ more likely to obtain such a rating.

\section{Discussion}

Our data analysis results showed that a social capital variable - constraint in one's social networks - was a statistically significant predictor of whether an IT professional will exceed performance expectations, after controlling for human capital variables such as age, job grade, and job tenure. This is consistent with prior research showing that appropriate connectivity in wellmanaged networks within organizations can have a substantial impact on performance, learning and innovation (Cross \& Parker, 2004). Individuals well-positioned in employee networks are more likely to be promoted, to obtain higher salaries (Burt, 1992), to exert greater influence in decision making (Friedken \& Johnson, 1998), and to foster innovation (Ibarra, 1993a). Prior research, however, has not sufficiently explored the relationship between social network position and individual employee performance (Ahuja, Galletta, \& Carley, 2003; Mehra et al., 2001; Sparrowe, 2001). Our findings remedy this deficiency.

From an informing science perspective, this study also contributes to our understanding of the Informing Science Framework (E. B. Cohen, 2009). Social capital and networks are examples of today's complex phenomena that are transdisciplinary in nature (E. B. Cohen, 2009). By applying a transdisciplinary network analysis method, we achieve a deeper understanding of social networks as an informing channel. The informing channel is one of the four future research areas Cohen (2009) proposes. In this respect, social networks warrants close study because, in our connected information society, they constitute a prominent channel through which people become informed. This is not a linear channel where information flows from an "informer" to a "client," but a network where every individual can be an informer and a client at the same time.

For research related to informing channels, a worthy area for major discoveries is the role played by informer/client characteristics (E. B. Cohen, 2009). Our research findings offer a number of insights into how IT professionals' social and human capital variables may affect their ability to tap social networks available to them, hence affecting their job performance.

\section{Constraint}

Many tools, methods, and techniques were implemented to improve employee performance. Research on social networks has shown that certain aspects of network position can have an impact on individual effectiveness, yet relatively little research has been conducted to connect one's network position to his/her performance (Flap \& Volker, 2004; Mehra et al., 2001; Sparrowe, 2001).

This study examines the effect of social capital on performance. Thus, identifying particular network variables as potential predictors of performance could prove influential in the development 
of organizational performance improvement programs. In addition, we analyzed human capital variables in relation to performance. Knowledge of potential relationships between these variables and performance would contribute further to the body of knowledge of performance improvement and potential causal factors.

For example, our findings provide significant implications for organizations when considering performance improvement initiatives. From a human resource standpoint, the evaluation of individual performance is a vital measure of employee effectiveness that virtually all organizations develop and monitor through performance management systems and methods. Millions of dollars a year are spent on state-of-the-art performance management systems, developed to enable employees and organizations to succeed. If network analysis can reveal key social network components that are related to employee performance, individuals and organizations could benefit and gain competitive advantage in the marketplace.

From the employees' standpoint, our study points out the importance of maintaining social networks, including the ability to bridge to other groups. Effective actions include: (a) get to know other group members' expertise and envision how to achieve synergy; (b) learn why and how to work together to achieve synergy of expertise; (c) participate in cross-functional groups; (d) spend time and effort on professional and personal development; (e) learn to communicate well; (f) match words and deeds; (g) build a reputation for competence; (h) be trustworthy (Cross \& Parker, 2004; Levin \& Cross, 2004).

Social network studies can enhance our understanding of knowledge management. Levin and Cross (2004) argue that structural, relational, and knowledge characteristics all have influence on the success of knowledge transfer. A social network is an important type of structure surrounding a person's acquisition of knowledge. Their study finds that, compared with intra-group ties, a person's ability to reach out to heterogeneous groups has a stronger effect on receipt of useful knowledge (Levin \& Cross, 2004). Similarly, our study shows that those individuals who are less constrained, i.e., better positioned to bridge across holes in the network structure, benefit from such ability as well.

At the business unit level, the same is true. It is likely that social interaction among business units promotes knowledge sharing, which, in turn, enhances performance (Tsai, 2002). As a negative example, Cross and Parker (2004) recount a case in which, despite good intention and deliberate organizational design, knowledge integration failed between two groups. The causes were that (a) the groups focused on promoting intra-group homogeneity and (b) the key person who bridged the two groups did not fulfill his role in knowledge integration. It is worth noting that, due to his bridging position, this person achieved a high performance rating at the expense of the integration effort. Therefore, it is interesting for researchers to explore further both the positive and negative consequences that the knowledge advantage of a less constrained network position can cause.

A knowledge management issue that has been explored at the inter-unit level is knowledge complexity. The advantage of less constrained positions may be more pronounced when less complex or explicit knowledge is of concern. Research findings, however, are not consistent regarding this. A previous study shows that weak inter-unit ties improve project performance when knowledge is not complex, while strong intra-unit ties facilitate the transfer of complex knowledge (Hansen, 1999). However, another study does not find support for this conclusion and discovers that strong ties can have a suppression effect on the weak ties (Levin \& Cross, 2004). The relationships between tie strength and tacit versus explicit knowledge, therefore, is an interesting direction for future studies.

At the inter-organizational level, the findings are similarly inconclusive. Both studying biotechnological firms, Walker, Kogut, and Shan (1997) conclude that companies prefer strong ties, whereas Cross and Parker (2004) find that weak ties between internal R\&D scientists and external 
groups of academics are preferred. The difference in their findings, however, can be function of the sample: startups in the former study, a major player in the industry in the latter. Regardless of the level of analysis, it is certain that "[k]nowledge sharing involves a complex social process that demands collaborative efforts. Social interaction is indispensable in this process as it can create trust and foster cooperation" (Tsai, 2002, p. 187).

\section{Job Grade}

In this study we found that IT employees in managerial positions (e.g., CIOs, directors) were more likely to achieve better performance ratings than those in technical positions (e.g., analysts). In addition, those in senior management positions performed better than those at lower levels. The statistically significant relationship between job grade and performance ratings was consistent with prior findings. Burt (2005) noted that on average, "people in higher job ranks manage across more structural holes, with access to larger and less constrained networks with shorter path distances between individuals" (p. 21). Befort and Hattrup (2003) find that managerial experience was positively related to perceptions of the importance of contextual performance behaviors reflecting compliance and extra effort.

Differences in formal rank are likely to influence patterns of interaction in organizations. Highranking individuals, by virtue of their control over resources and their decision-making authority, may be better positioned to emerge as central players in social networks (Ibarra, 1993a, 1993b; Lincoln \& Miller, 1979).

\section{Job Tenure}

We found a significant inverse relationship between job tenure and performance ratings. Thus, the more experience one had on the job, the less likely it was that he/she would exceed performance expectations. Although this may seem counter-intuitive, it is, in fact, likely the case for employees with long job tenure (in our study, the mean tenure is 15.51 years). During the early stage of job tenure, while one is learning his/her job, experience enhances performance. However, as tenure lengthens, the influence of the learning that comes with experience weakens (Hunter \& Thatcher, 2007; Schmidt \& Hunter, 2004). In fact, Sturman (2003) performed a meta-analysis of the literature on the relationship between temporal factors and performance and suggested an inverted U-shape relationship. That is, at higher levels, job tenure can have negative impact on performance.

From a social network perspective, the length of time a person has been with the company is also likely to affect the pattern of participation in social networks. Individuals who have been with the company longer may be more likely to occupy central positions in social networks (Mehra et al., 2001). Therefore, employees with longer job tenure tend to have larger and/or denser networks. Instead of tapping this capital for doing their jobs better, they may be so busy maintaining the network ties per se that their work performance suffers (Burt \& Ronchi, 1990). Performance evaluations have been shown to reveal a weak positive correlation with network size, as well as a weak negative effect with network hierarchy. There is a tendency for people with dense networks to receive lower performance evaluations (Burt, 2000). It will be interesting for future research to scrutinize further the relationships among job tenure, social network size/density, and job performance.

\section{Age}

This study revealed a marginally significant relationship $(p=.057)$ between age and performance ratings. It is widely believed that job productivity declines with age (Rhodes, 1983). The inverse relationship between age and performance we found supported this assertion. Studies of industrial 
jobs using performance ratings suggest that although older workers are rated as highly as younger workers with respect to overall efficiency, they tend to receive lower ratings for speed of work and learning ability (Sparrow \& Davies, 1988). Waldman and Avolio (1986) concluded that the relationship between age and productivity was substantially different depending on the way that performance was evaluated. Based on supervisory ratings (as used in this study), age and performance were negatively correlated. In general, chronological age accounted for only a small percentage of variance in job performance. Studies that have examined the effects of age and length of service on job performance indicate that when length of service is controlled, age differences in performance may sometimes disappear entirely (Giniger, Dispenzieri, \& Eisenberg, 1983; Schwab \& Heneman, 1977), suggesting that the effects of experience at the job may counteract the effects of age. Age differences that are often clear in the laboratory or in a small sample field setting may be masked by variables such as job complexity, training, and tenure in a large sample field setting (Sparrow \& Davies, 1988).

\section{Limitations}

There are a number of limitations to our study. First, we used a single measurement of performance. Multiple observations of performance, where "ratings are not solely a product of one person's feelings toward another but are derived from peer evaluations, supervisor project ratings, and objective metrics such as billable hours" (Cross \& Cummings, 2004, p. 935), would have been a stronger measure. Due to the sensitivity of human resource records and other resource restrictions, we were unable to use more robust measures of employee performance besides supervisor ratings. Future researchers may consider using multi-dimensional measures of performance. Such an approach also would allow examination of how different network profiles might be associated with other dimensions of performance, such as efficiency, effectiveness, and innovation.

Secondly, this study only explored the relationship between performance and one single measure of network position, constraint. In future research, it would be beneficial to consider other measures, including centrality, network size, and density. However, constraint is a good, general indicator of one's network positions.

Thirdly, care should be exercised when interpreting or applying the findings from this study. They may not be generalizable to all people or settings. Social network research covers different types of network ties that may span across different levels of analysis (Kilduff \& Tsai, 2003). As our discussion on knowledge management showed, although some research findings are consistent across all levels, complexity and inconclusiveness may result when extrapolating others. Also, the effect of social networks can differ in different cultures, both in terms of profession and nationality (Cross \& Parker, 2004). Like many prior studies, we studied knowledge workers whose performance relies on the quality of informing. For individuals whose determining factors for performance are different, it is likely that our findings will not hold and new studies are needed.

Lastly, our study collected performance data at a single point in time. The absence of longitudinal data calls for additional analysis to be performed with the existing sample, if possible, over an extended period to determine potential positive or negative trends in the data. Measurements of such performance improvements over time would yield more "hard" data in terms of the performance variables and provide more insight into the performance-network position relationship.

\section{Conclusion}

Studies of employee social networks have revealed potential competitive advantages for organizations and individuals. For IT professionals, whose performance depends a lot on the acquisition of technical and organizational knowledge, their social networks are an indispensable informing 
channel. However, extant research on the impact of social networks on knowledge workers has predominantly focused on R\&D staff (e.g., Brookes et al., 2007; Lee et al., 2005). In this study, we examined the relationship between characteristics of IT professionals' social networks and their performance. We found that a particular trait of an IT professional - his/her constraint in social networks, hence his/her ability to span the "structural holes" - did impact on his/her job performance. This major finding enriches our understanding of the Informing Science Framework (E. B. Cohen, 2009) in that it explicates possible human agency to expand the informing channel. If an IT professional can recognize the role of his/her social networks in channel expansion and work to extend the reach of his/her networks, he/she stands a better chance at satisfactory job performance. Our findings related to human capital variables suggest that technically oriented and lower-level managerial positions are less prone to favorable performance ratings. The socialnetwork explanation may be that networked resources are not as critical to these positions as to top-level managerial positions. IT professionals who vie for managerial-track promotion should then seriously consider the importance of building social networks. We also find inverse relationships between age/job tenure and performance, which alert us to the possible detriment of building the networks for the sake of network expansion. The decisive factor is to take advantage consciously of the rich informing sources that social networks afford and to use them to enhance job performance.

\section{References}

Ahuja, M. K., Galletta, D., \& Carley, K. (2003). Individual centrality and performance in virtual R\&D groups: An empirical study. Management Science, 49(1), 21-38.

Arvey, R. D., \& Murphy, K. R. (1998). Performance evaluation in work settings. Annual Review of Psychology, 49(1), 141-159.

Athanassiou, N., \& Nigh, D. (1999). The impact of U.S. company internationalization on top management team advice networks: A tacit knowledge perspective. Strategic Management Journal, 20(1), 83-92.

Baker, W. (2000). Achieving success through social capital. San Francisco, CA: Jossey-Bass.

Bavelas, A. (1950). Communication in task-oriented groups. Journal of the Acoustical Society of America, $22,271-282$.

Befort, N., \& Hattrup, K. (2003). Valuing task and contextual performance: Experience, job roles and ratings of the importance of job behaviors. Applied HRM Research, 8(1-2), 17-32.

Borgatti, S., Everett, M., \& Freeman, L. (1992). UCINET IV version 1.0 reference manual. Columbia, SC: Analytic Technologies.

Boxman, E. A., De Graaf, P. M., \& Flap, H. D. (1991). The impact of social and human capital on hte income attainment of Dutch managers. Social Networks, 136, 51-73.

Brass, D. J. (1984). Being in the right place: A structural analysis of individual influence in an organization. Administrative Science Quarterly, 29, 518-539.

Brass, D. J., \& Burkhardt, M. E. (1993). Potential power and power use: An investigation of structure and behavior. Academy of Management Journal, 36, 440-470.

Bretz, R. D., Milkovich, G. T., \& Read, W. M. (1992). The current state of performance appraisal research and practice: Concerns, directions and implications. Journal of Management, 18(2), 321-344.

Brookes, N. J., Morton, S. C., Grossman, S., Joesbury, P., \& Varnes, D. (2007). Analyzing social capital to improve product development team performance: Action-research investigations in the aerospace industry with TRW and GKN. IEEE Transactions on Engineering Management, 54(4), 814-830.

Burt, R. S. (1992). Structural Holes: The social structure of competition. Cambridge, MA: Harvard University Press. 
Burt, R. S. (2000). Structural holes versus network closure as social capital. In N. Lin, K. Cook \& R. S. Burt (Eds.), Social capital: Theory and research (pp. 31-56). New York, NY: Aldine de Gruyter.

Burt, R. S. (2005). Brokerage and closure. Oxford, UK: Oxford University Press.

Burt, R. S., Hogarth, R. M., \& Michaud, C. (2000). The social capital of French and American managers. Organization Science, 11(2), 123-147.

Burt, R. S., \& Ronchi, D. (1990). Contested control in a large manufacturing plant. In J. Weesie \& H. D. Flap (Eds.), Social networks through time (pp. 121-157). Utrecht: Isorph.

Cohen, D., \& Prusak, L. (2001). In good company. Boston, MA: Harvard University Press.

Cohen, E. B. (1999). Reconceptualizing information systems as a field of the transdiscipline informing science: From ugly duckling to swan. Journal of Computing and Information Technology, 7(3), 213219.

Cohen, E. B. (2009). A philosophy of informing science. Informing Science: the International Journal of an Emerging Transdiscipline, 12, 1-15. Retrieved from http:/www.inform.nu/Articles/Vol12/ISJv12p001-015Cohen399.pdf

Cohen, J., Cohen, P., West, S. G., \& Aiken, L. S. (2003). Applied multiple regression/correlation analysis for the behavioral sciences. Mahwah, NJ: Lawerence Erlbaum Associates.

Coleman, J. (1988). Social capital in the creation of human capital. American Journal of Sociology, 94, 95120.

Cross, R., \& Cummings, J. (2004). Tie and network correlates of individual performance in knowledgeintensive work. Academy of Management Journal, 47(6), 928-937.

Cross, R., \& Parker, A. (2004). The hidden power of social networks. Boston, MA: Harvard Business School Press.

Erickson, B. (2001). Good networks and good jobs: The value of social capital to employers and employees. In N. Lin, K. Cook \& R. S. Burt (Eds.), Social capital: Theory and research (pp. 127-158). New York, NY: Aldine de Gruyter.

Fernandez, R. M., Castilla, E. J., \& Moore, P. (2000). Social capital at work: Neworks and employment at a phone center. American Journal of Sociology, 105(5), 1288-1356.

Field, A. (2005). Discovering statistics using SPSS. London, UK: Sage Publications, Ltd.

Flap, H. D., \& Volker, B. (2004). Social networks and performance at work. In H. D. Flap \& B. Volker (Eds.), Creation and returns of social capital (pp. 172-196). London, UK: Routledge.

Friedken, N. E., \& Johnson, E. C. (1998). A structural theory of social influence. Cambridge, MA: Cambridge University Press.

Giniger, S., Dispenzieri, A., \& Eisenberg, J. (1983). Age, experience and performance on speed and skill jobs in an applied setting. Journal of Applied Psychology, 68, 469-475.

Granovetter, M. S. (1973). The strength of weak ties. American Journal of Sociology, 78(6), 1360-1380.

Granovetter, M. S. (1983). The strength of weak ties: A network theory revisited. Sociological Theory, 1, 201-233.

Granovetter, M. S. (1985). Economic action and social structure: The problem of embeddedness. American Journal of Sociology, 91, 481-510.

Hair, J. F., Black, W. C., Babin, B. J., Anderson, R. E., \& Tatham, R. L. (2006). Multivariate data analysis (6th ed.). Upper Saddle River, NJ: Prentice-Hall.

Hansen, M. T. (1999). The search-transfer problem: The role of weak ties in sharing knowledge across organizational subunits. Administrative Science Quarterly, 44(82-111). 
Hunter, L. W., \& Thatcher, S. M. B. (2007). Feeling the heat: Effects of stress, commitment, and job experience on job performance. Academy of Management Journal, 50(4), 953-968.

Ibarra, H. (1993a). Network centrality, power, and innovation involvement: Determinants of technical and administrative roles. Academy of Management Journal, 36(3), 471-502.

Ibarra, H. (1993b). Power, social influence, and sense making: Effects of network centrality and proximity on employee perceptions. Administrative Science Quarterly, 38(2), 277-303.

Inkpen, A., \& Tsang, E. (2005). Social capital, networks and knowledge transfer. Academy of Management Review, 30(1), 26-44.

Kaše, R., Paauwe, J., \& Zupan, N. (2009). HR practices, interpersonal relations, and intrafirm knowledge transfer in knowledge-intensive firms: A social network perspective. Human Resources Management, 48(4), 615-639.

Kilduff, M., \& Tsai, W. (2003). Social networks and organizations. Thousand Oaks, CA: Sage Publications.

Knoke, D., \& Yang, S. (2008). Social network analysis (2nd ed.). Thousand Oaks, CA: SAGE Publications.

Lee, S.-H., Wong, P.-K., \& Chong, C.-L. (2005). Human and social capital explanations for R\&D outcomes. IEEE Transactions on Engineering Management, 52(1), 59-68.

Levin, D. Z., \& Cross, R. (2004). The strength of weak ties you can trust: The mediating role of trust in effective knowledge transfer. Management Science, 50(11), 1477-1490.

Lin, N. (1999). Social networks and status attainment. Annual Review of Sociology, 25, 467-487.

Lin, N. (2001). Social capital: A theory of social structure and action. New York, NY: Cambridge University Press.

Lincoln, J. R., \& Miller, J. (1979). Work and friendship ties in organizations: A comparative analysis of relationship networks. Administrative Science Quarterly, 24, 181-199.

Major, D. A., Davis, D. D., Germano, L. M., Fletcher, T. D., Sanchez-Hucles, J., \& Mann, J. (2007). Managing human resources in information technology: Best practices of high-performance supervisors. Human Resources Management, 46(3), 411-427.

Markovsky, B., Skvoretz, J., Willer, D., Lovaglia, M., \& Erger, J. (1993). The seeds of power: Extending network exchange theory. American Sociological Review, 58(197-209).

Marsden, P. V. (1987). Core discussion networks of Americans. American Sociological Review, 52, 122131.

Marsden, P. V. (1990). Network data and measurement. Annual Review of Sociology, 16, 435-463.

McCluskey, T., \& Korobow, A. (2009). Leveraging networks and social software for mission success. The Public Manager, 38(2), 66-70.

Mehra, A., Kilduff, M., \& Brass, D. J. (2001). The social networks of high and low self monitors: Implications for workplace performance. Administrative Science Quarterly, 46, 121-146.

Mizruchi, M., \& Sterns, L. B. (2001). Getting deals done: The use of social networks in bank decision making. American Sociological Review, 66, 647-671.

Podolny, J., \& Baron, J. (1997). Resources and relationships: Social networks and mobility in the workplace. American Sociological Review, 62, 673-693.

Powell, W., Koput, K., \& Smith-Doer, L. (1996). Interorganizational collaboration and the locus of innovation: Networks of learning in biotechnology. Administrative Science Quarterly, 41, 116-145.

Reagans, R., \& McEvily, I. (2003). Network structure and knowledge transfer: The effects of cohesion and range. Administrative Science Quarterly, 48(2), 240-267. 
Rhodes, S. R. (1983). Age-related difference in work attitudes and behavior: A review and conceptual analysis. Psychological Bulletin, 93, 328-367.

Robert, L. P., Dennis, A. R., \& Ahuja, M. K. (2008). Social capital and knowledge integration in digitally enabled teams. Information Systems Research, 19(3), 314-334.

Sanders, K., \& Hoekstra, S. (1998). Informal networks and absenteeism within an organization. Computational and Mathematical Organizational Theory, 49, 149-163.

Schmidt, F. L., \& Hunter, J. E. (2004). General mental ability in the world of work: Occupational attainment and job performance. Journal of Personality and Social Psychology, 86, 162-173.

Schwab, D. P., \& Heneman, H. G. (1977). Effects of age and experience on productivity. Industrial Gerontology, 4, 113-117.

Scullen, S. E., \& Mount, M. K. (2000). Understanding the latent structure of job performance ratings. Journal of Applied Psychology, 85(6), 956-970.

Shaw, M. E. (1971). Group Dynamics: The psychology of small group behavior. New York, NY: McGrawHill.

Sparrow, P. R., \& Davies, D. R. (1988). Effects of age, tenure, training and job complexity on technical performance. Psychology and Aging, 30(3), 307-314.

Sparrowe, R. T. (2001). Social networks and the performance of individuals in groups. Academy of Management Journal, 44(2), 316-325.

Sparrowe, R. T., \& Liden, R. (1997). Process and structure in leader-member exchange. Academy of Management Review, 22, 522-552.

Sturman, M. C. (2003). Searching for the inverted U-shaped relationship between time and performance: Meta-analyses of the experience/performance, tenure/performance, and age/performance relationships. Journal of Management, 29(5), 609-640.

Sykes, T. A., Venkatesh, V., \& Gosain, S. (2009). Model of acceptance with peer support: A social network perspective to understand employees' system use. MIS Quarterly, 33(2), 371-393.

Tsai, W. (2002). Social structure of "coopetition" within a multiunit organization: Coordination, competition, and intraorganizational knowlege sharing. Organization Science, 13(2), 179-190.

Tsai, W., \& Ghosal, S. (1998). Social capital and value creation: The role of intrafirm networks. Academy of Management Journal, 41(4), 464-476.

Waldman, D. A., \& Avolio, B. J. (1986). A meta-analysis of age differences and job performance. Journal of Applied Psychology, 71, 33-38.

Walker, G., Kogut, B., \& Shan, W. (1997). Social capital, structural holes and the formation of an industry network. Organization Science, 8(2), 109-125.

Wasko, M. M., \& Faraj, S. (2005). Why should I share? Examining social capital and knowledge contribution in electronic networks of practice. MIS Quarterly, 29(1), 35-57.

Yang, S., Lee, H., \& Kurnia, S. (2009). Social capital in information and communications technology research: Past, present, and future. Communications of the AIS, 25, 184-220. 


\section{Biographies}

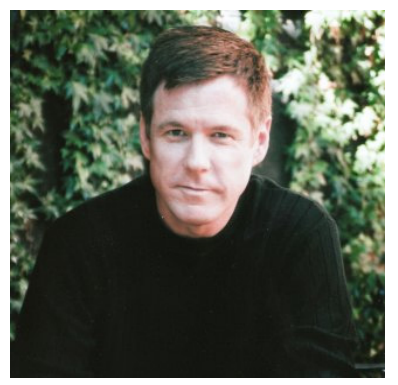

Paul Burton, Ph.D. is a Project Manager for a large defense company with over 20 years experience in Information Technology. Dr. Burton has focused on transformational change and the adoption of new technologies for major organizations. His expertise includes current trends in technology through network analysis, collaborative tools, performance improvement, and technology adoption. His Doctoral research focused on components of social networks as enablers of performance in organizations. He has also served as an Organizational Change Consultant for Computer Sciences Corporation (CSC), and held various roles in Information Technology at Electronic Data Systems (EDS). Industry experience includes financial services, government, oil \& gas, and defense, with international experience in Europe and the Middle East. He holds a Ph.D. in Applied Technology and an M.B.A. from the University of North Texas, and is an active member of the university's Center for Decision and Information Technologies.

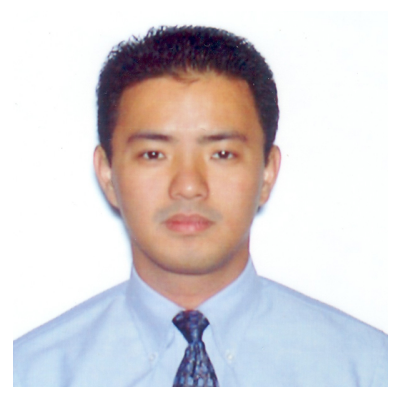

Yu "Andy" Wu is an assistant professor in the Department of Information Technology and Decision Sciences, College of Business at the University of North Texas. He received a Ph.D. in Management Information Systems from the University of Central Florida, Orlando, FL, in 2007. His primary research interests include social networks and information security. His research papers appeared in various information systems journals and conferences. Before his academic career, Dr. $\mathrm{Wu}$ had seven years' experiences in various business and management positions.

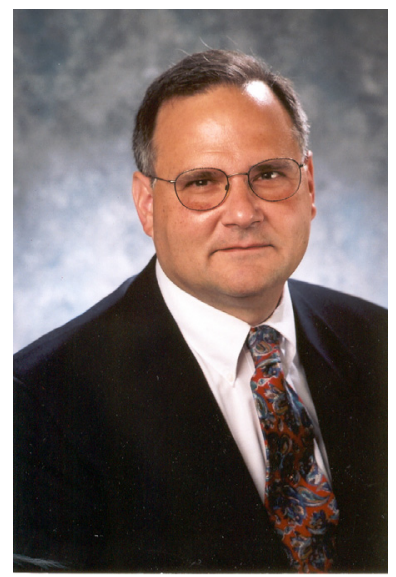

Victor R. Prybutok is a Regents Professor of Decision Sciences in the Information Technology and Decision Sciences Department and Coordinator of the ITDS Department Doctoral Program in the College of Business at the University of North Texas. He received, from Drexel University, his B.S. with High Honors in 1974, a M.S. in BioMathematics in 1976, a M.S. in Environmental Health in 1980, and a Ph.D. in Environmental Analysis and Applied Statistics in 1984. Dr. Prybutok is an ASQ certified quality engineer, certified quality auditor, certified manager of quality / organizational excellence, and served as a Texas Quality Award Examiner in 1993. Dr. Prybutok has authored over 100 journal articles, several book chapters, and more than 70 conference presentations in information systems measurement, quality control, risk assessment, and applied statistics. 